\title{
A taxonomy of types of epistemic dependence: introduction to the Synthese special issue on epistemic dependence
}

\author{
Fernando Broncano-Berrocal ${ }^{1}$. Jesús Vega-Encabo ${ }^{1}$ \\ Published online: 9 May 2019 \\ (c) Springer Nature B.V. 2019
}

What is epistemic dependence? There is no unique answer to this question. In its most general form, the notion of epistemic dependence can be articulated with the following schema:

DEP: $x$ depends on $y$ to $\phi$.

Epistemic dependence, as characterized by DEP, is a goal-oriented relation, in that $x$ 's reliance on $y$ is for the achievement of some epistemic goal $(\phi) .{ }^{1}$ We can thus distinguish different types of epistemic dependence in terms of what kind of goal the state of being epistemically dependent on aims at. ${ }^{2}$

\section{Types of epistemic dependence in terms of epistemic goals}

A characteristic epistemic goal of epistemic dependence relations is the achievement of some epistemic standing, such as knowledge, justification, understanding, wisdom or certainty. Accordingly, epistemic dependence is knowledge-relative if $x$ depends on $y$ to qualify as knowledge, or to know $p$; justification-relative if $x$ depends on $y$ to

\footnotetext{
${ }^{1}$ Epistemic dependence is to be distinguished from ontological dependence (e.g., the dependence of one entity for its existence upon another entity; see Koslicki (2013) and Tahko and Lowe (2015) for two overviews of the literature) as well as from causal dependence, which is a key notion in David Lewis's counterfactual account of causation-see Lewis (1973).

2 Zangwill (Forthcoming) offers an alternative notion of epistemic dependence which is not goal-oriented. According to this notion, epistemic facts (e.g., knowledge) partially or fully depend on non-epistemic facts, which is an instance of a more general form of dependency between evaluative and non-evaluative facts. In Zangwill's words, "knowledge cannot be bare in the same sense that evaluative properties quite generally cannot hold barely. If we know something then there must be something in virtue of which we know it, just as if an action is bad then there must be something about the action in virtue of which it is bad" (Zangwill Forthcoming: p. 3).
}

Fernando Broncano-Berrocal

fernando.broncano@uam.es

1 Autonomous University of Madrid, Madrid, Spain 
be epistemically justified, or to be justified in believing $p$; understanding-relative if $x$ depends on $y$ to understand $p$; and so on.

However, epistemic goals other than achieving epistemic standings can figure in DEP and, therefore, other types of epistemic dependence can be distinguished. By way of illustration, by depending on something or someone else one might seek some sort of cognitive enhancement, such as an improvement in the reliability of one's cognitive abilities or the acquisition of new intellectual virtues. Another possibility is that one depends on something or someone else to comply with one's epistemic obligations. For example, if there is such a thing as an epistemic duty to avoid dogmatism and close-mindedness, someone who is dogmatic and close-minded-because always depends on sources of information that point in the same direction-might rely on alternative sources that offer countervailing evidence to become more reasonable and open-minded, thus discharging her epistemic duty.

Finally, these different types of epistemic dependence are defined in terms of achieving epistemic goals such as the acquisition of different epistemic standings, enhancing one's cognitive faculties or complying with one's epistemic duties. Epistemic dependence in this sense is positive. However, when being in an epistemic dependence relation has the consequence that such goals are not accomplished (e.g., when epistemically depending on someone makes one lose one's knowledge), then epistemic dependence becomes negative. ${ }^{3}$

\section{Types of epistemic dependence in terms of relata: belief-based versus agent-based epistemic dependence}

Prior to the question of what kinds of epistemic goals does the epistemic dependence relation aim at, there is a more fundamental question whose answer helps distinguishing further forms of epistemic dependence:

What depends on what epistemically, i.e., what are the relata of the epistemic dependence relation?

One possibility is that the ' $x$ ' in DEP stands for a belief and that epistemic dependence is thus belief-based. One type of belief-based dependence arises when a belief depends on other beliefs to be justified or qualify as knowledge. This sort of epistemic dependence first appears in the context of foundationalism, which is roughly the view that the justification of a belief derives from (i.e., depends upon) the justification of other beliefs and ultimately on a foundation (e.g., basic beliefs, perceptual sources) that need not be justified by anything else. ${ }^{4}$ Another possibility is that a belief depends on reasons to be justified. This form of belief-based dependence has been extensively discussed in the literature on epistemic reasons and more specifically in the context

\footnotetext{
3 See Pritchard (2015) for further discussion on the distinction between positive and negative epistemic dependence.

4 See Kornblith (1980), Audi (1983) and more recently Oakley (2006) for discussion of the notion of epistemic dependence in the context of foundationalism.
} 
of the epistemic basing relation (i.e., the relation between a reason and a belief when the belief is held for that reason) ${ }^{5}$

However, although interesting consequences can be drawn for the notions of knowledge and justification when epistemic dependence is understood as a belief-based relation (i.e., as a relation between a belief and something else), the epistemic dependence relation is best interpreted, more broadly, as involving agents and not merely their beliefs. As we will see next, understanding epistemic dependence as a relationship between an agent and something or someone else adds an extra layer of complexity and philosophical interest, first, because several types of agent-based epistemic dependence can be distinguished in terms of what is that the agent depends on to accomplish epistemic goals such as the ones distinguished in Sect. 1, and second, because as we will see in Sects. 5 and 6 these forms of agent-based dependence bear on normative questions concerning a variety of epistemological issues such as epistemic authority, intellectual autonomy, epistemic rationality, testimony, disagreement, expertise or virtue epistemology.

\section{Types of agent-based epistemic dependence}

We are social beings and as such we are highly dependent on others to succeed in our practical endeavors. The epistemic domain is not different: we depend on other agents to achieve our epistemic goals. More specifically, while we often place our epistemic trust on other individuals, it is not on agents as such that we are epistemically dependent on, but upon their epistemic standings (e.g., the fact that they hold justified or knowledgeable beliefs) as well as upon their epistemic practices. Interestingly, the kind of epistemic practice we are most dependent on are testimonial exchanges, so the most common type of agent-based epistemic dependence is dependence on assertions by others.

However, testimony is not the only factor that gives shape to the epistemic dependence relation on others. Another parameter is the degree of expertise of the epistemically dependent agent with respect to the degree of expertise of the subject she is dependent on. Accordingly, another form of agent-based dependence is dependence on the expertise of others. Relatedly, being an expert on some matter often goes hand-in-hand with being authoritative about it. This factor also provides another axis along which the epistemic dependence relation can be assessed. We can thus talk of dependence on the epistemic authority of others.

In addition, we belong to groups and we may thus depend on the epistemic practices of these collectives. Interestingly, this interaction-epistemic dependence on collectives - comes in two guises. One possibility is that members of a collective depend on each other to achieve collective epistemic goals. This often happens in science, where scientific inquiry can be properly understood as a collective enterprise characterized by a marked division of cognitive labor in which scientists mutually

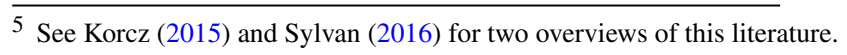


depend on each other to advance the state of knowledge in their fields. ${ }^{6}$ It is not obvious and hence philosophical argumentation is needed to establish whether this variety of epistemic dependence constitutes genuine dependence on collectives (e.g., on the scientific community as a whole) or whether it can be simply interpreted as a more complex form of epistemic dependence on individuals than one-to-one dependence. $^{7}$

Another possibility is that an agent depends on the epistemic practices of a collective to achieve her individual epistemic goals. As before, the extent to which this form of agent-based dependence is genuine epistemic dependence on collectives (and not a complex instance of epistemic dependence on individual agents) depends on whether or not the epistemic practices and epistemic standings of collectives are over and above the epistemic practices and epistemic standings of their individual members. ${ }^{8}$ By way of illustration, we often depend on the testimony of groups to acquire knowledge or justified beliefs. For example, one might learn from a report by the World Health Organization that breastfeeding within an hour after birth is critical for saving newborn lives. If WHO's testimony is reducible to the testimony of its members (or to some way of aggregating their individual assertions), then WHO's testimony is not distinct from the testimony of its members and hence relying on this collective to know that proposition is simply an instance of epistemic dependence on individual agents. By contrast, if group testimony can be properly considered a source of knowledge and justified belief in itself, it should be possible for an agent to epistemically depend on a collective as such for acquiring these epistemic standings. ${ }^{9}$

Some authors, instead of talking of collective epistemic dependence, distinguish a broader form of epistemic dependence on social environments or epistemic communities. ${ }^{10}$ Although there is no clear-cut definition of what these notions amount to, they may be thought as encompassing collectives, individuals and more broadly the set of information sources typically available to an agent (e.g., her social relationships, the newspapers she reads, the radios and podcasts she listens to, the social networks she belongs to, and so on). Goldberg (2011), in particular, dubs this kind of epistemic dependence on communities or social environments diffuse as opposed to direct epistemic dependence on individuals. More specifically, Goldberg claims that diffuse epistemic dependence occurs when changes in the practices, states, and dispositions of the members of a community or social environment (e.g., well-regulated practices for monitoring and policing testimony) provoke changes in the epistemic properties of a subject's belief, where the effect remains when the effects of any direct epistemic dependence are subtracted. By direct epistemic dependence, he means the kind

\footnotetext{
6 See Kitcher (1990) for a seminal paper on the division of cognitive labor in science. See Goldberg (2011) for a paper on the division of epistemic labor more generally.

7 See Hardwig (1985), Andersen and Wagenknecht (2013), de Ridder (2014), Wagenknecht (2014, 2015), and Andersen (2016) for discussions of epistemic dependence in the context of science.

8 See Dewitt (2012) for discussion of how individuals can use group agents as sources of epistemic dependence.

9 Whether or not group testimony is a source of knowledge and justification in itself is an open question. See Lackey (2015) for an in-depth discussion of the topic, where she argues against non-reductionist accounts. 10 See Goldberg (2010: 178 ff., 2011), Gelfert (2013) and Goldberg's and Greco's respective contributions to this volume for further discussion on social environments and epistemic communities.
} 
of dependence that happens when changes in the epistemic properties of a subject's belief are due to changes in the epistemic perspective of another subject, as it often occurs in testimony.

We have considered forms of agent-based epistemic dependence in which an agent relies on another agent (whether individual or collective) to achieve an (individual or collective) epistemic goal. However, we can also epistemically depend on instruments - e.g., measuring instruments (clocks, thermometers, speedometers), computing machines (calculators, computers), cognitive enhancement devices (microscopes, binoculars, hearing aids), and so on-to achieve epistemic standings (e.g., knowledge, understanding, justified beliefs) either directly, by placing our trust on them, or indirectly, by coupling or cognitively integrating them with our cognitive apparatus. Many of these instruments exploit physical regularities to provide valuable information. This could suggest that epistemic dependence on instruments simply amounts to epistemic dependence on physical regularities. After all, in the same way as one can rely on physical regularities (e.g., sunrises) to achieve epistemic goals such as knowing (e.g., knowing when to have breakfast), one can rely on instruments, which regularly provide certain kinds of information, to cover one's informational needs. However, there is a difference between epistemically depending on physical regularities and instruments: the latter are specifically designed and manufactured to provide specific kinds of information. In this sense, unlike mere reliance on regularities, epistemic dependence on instruments is agentinvolving. ${ }^{11}$

Finally, there is something that all forms of agent-based epistemic dependence share (whether epistemic dependence on instruments, physical regularities, other agents or social environments), which suggest a general characterization of the phenomenon: they all involve factors that are beyond one's cognitive agency. ${ }^{12}$ This can be further specified as follows: when $S$ depends on a set of extra-agential factors $F$ to achieve some epistemic goal $E, S$ 's successful achievement of $E$ is to a certain degree due to the exercise of her cognitive abilities and to a certain degree due to $F$. Thus, the larger the extent to which $F$ explains the fact that $S$ achieves $E$, the more $S$ epistemically depends on $F{ }^{13}$ Another way to put it is this: $S$ epistemically depends on $F$ more or less, when variations on $F$ have more or less impact on whether or not $S$ achieves $E$ than variations in the exercise of S's cognitive abilities-it goes without saying that agent-based epistemic dependence comes in degrees.

\section{Types of epistemic dependence in terms of formal properties}

An alternative way to classify epistemic dependence relations is in terms of their formal properties and, in particular, in terms of whether or not they are reflexive, transitive or symmetrical relations.

\footnotetext{
11 The normative implications of this will become clearer in $\S 5$.

12 See Pritchard (2015) for this sort of characterization of the notion of epistemic dependence.

13 Similar considerations can be given for negative epistemic dependence.
} 


\subsection{Reflexive versus irreflexive epistemic dependence}

Consider agent-based dependence first. In a sense, we all depend on ourselves (and particularly, on our own cognitive abilities) to achieve epistemic standings such as knowledge and justified beliefs. Therefore, there are reflexive agent-based dependence relations. However, given our limited epistemic powers we often need to depend on others (typically on their testimony) to know and acquire justified beliefs about propositions that we couldn't possibly know or justifiably believe otherwise. In this sense, some agent-based dependence relations are irreflexive. ${ }^{14}$ So, in general, whether or not an agent-based dependence relation is reflexive largely depends on how well positioned the agent is (e.g., how reliable her cognitive abilities are) in relation to the relevant epistemic goal she pursues (e.g., acquiring knowledge about some specific set of propositions she is not in a position to know by her own means). By contrast, in the case of belief-based dependence things are different: except perhaps for some beliefs in cogito or hinge propositions, no belief can depend upon itself to qualify as knowledge or to be justified. Therefore, belief-based dependence is irreflexive.

\subsection{Transitive versus intransitive epistemic dependence}

If $A$ epistemically depends on $B$ to achieve some epistemic goal and $B$ epistemically depends on $C$ to achieve the same epistemic goal, does $A$ also epistemically depend on $C$ ? There is no unique answer to this question. Whether an agent-based dependence is transitive or intransitive hinges on the kind of dependence relation in question (and on how it is conceived) as well as on the relevant epistemic goal it is aimed at.

The case of testimony serves as an illustration of this. Some views in the epistemology of testimony entail that epistemic dependence on other people's assertions is transitive, whereas other views entail that it is intransitive. For instance, transmission theories of testimonial knowledge and justification roughly hold that testifiers need themselves to be in possession of knowledge or justification in order for recipients to acquire knowledge on the basis of their testimony. These views thus characterize epistemic dependence on testimony as a transitive relation. If these kinds of views are false, however, $A$ does not necessarily depend on $C$ 's testimony when trying to acquire knowledge from $B$ 's testimony if $B$ 's knowledge epistemically depends on $C$ 's testimony. In other words, if testimony itself generates new epistemic properties such as knowledge or justification, epistemically depending on assertions by others may be considered an intransitive relation. ${ }^{15}$ Relatedly, long testimonial chains might cause a loss of transitivity. As Fraser (2016: 13) points out, in such long chains "words can be misheard, sentences incorrectly disambiguated, and context-dependent constituents of sentences misinterpreted". This means that long testimonial chains may give rise to defeaters, with a corresponding impact on the epistemic properties transmitted (or generated) by the relevant testimony.

In the case of belief-based dependence, and most notably in the case of the kind of belief-on-belief dependence that appears in the context of foundationalism, epistemic

\footnotetext{
${ }^{14}$ As we will see later, this is relevant to the topic of intellectual autonomy.

15 See Lackey (2008) for extensive discussion of transmission theories.
} 
dependence is explicitly characterized as a transitive relation. After all, according to foundationalism, a belief's justification depends upon the justification of more fundamental beliefs which are in turn justified on the basis of yet more fundamental beliefs.

\subsection{Symmetrical versus asymmetrical epistemic dependence}

Many relations of epistemic dependence are asymmetrical. For example, if foundationalism is right, justified beliefs bear asymmetric relations of dependence to beliefs whose justification derives from a foundation of non-inferential justification. In the case of testimony, the relevant epistemic dependence relation between the hearer and the speaker is also asymmetrical. If $A$ depends on $B$ 's testimony that $p$ to know that $p$, it is not the case that $B$ depends on $A$ 's testimony that $p$ to know that $p$.

Are there symmetrical relations of epistemic dependence? We find them in cases where several individuals divide their cognitive labor in order to achieve a collective epistemic goal. In such cases, individual agents mutually depend on each other to accomplish a goal that they could not achieve on their own. ${ }^{16}$ In addition, if Hallson and Kappel are right in their contribution to this volume, cases of disagreement can be interpreted in this way: the disagreeing parties mutually depend on each other to achieve collective epistemic gains that they could not achieve if they were not in disagreement.

\section{Implications for debates in epistemology}

Having offered a taxonomy of types of epistemic dependence, we proceed to explain some implications of the phenomenon of agent-based epistemic dependence for ongoing debates in epistemology, as investigated by the essays of this special issue of Synthese.

\subsection{Epistemic authority and epistemic rationality: agents versus instruments}

In his seminal paper 'Epistemic dependence' (1985), John Hardwig first analyzed our dependence on the epistemic authority of others to acquire knowledge or justified beliefs, especially in connection with the question of whether or not it is rational to do so. Hardwig answers positively: it is rational to depend on epistemic authorities to form beliefs about propositions one is not authoritative about insofar as one has reasons to think that the more authoritative agents have good evidential reasons for the truth of these propositions, even if one is unaware of what their evidence is. In this way, according to Hardwig, reliance on experts is typically blind.

Interestingly, a consequence of this sort of epistemic dependence is that when one has reasons to think that one's own judgment is inferior to the judgment of more competent agents, it is rationally advisable not to make up one's own mind. Benjamin

\footnotetext{
16 See Andersen and Wagenknecht (2013) for further discussion on mutual epistemic dependence, which they call 'multilateral' dependence.
} 
McMyler ('On not making up one's own mind', in this volume) points out that this gives rise to a philosophical puzzle concerning the very notion of authority. In a nutshell, how can one make up one's own mind without doing it for oneself in conditions of dependence on others and on their authority in particular?

McMyler aims to answer this question without falling back onto the idea of surrendering one's own judgment or abdicating the epistemic responsibilities that come with the exercise of rational agency. In this sense, he aims to steer clear of the conclusion that when someone forms a belief on the authority of others, she does not count as herself judging that what the other agents tell her is true, and specifically of the idea that subjects make up their minds without doing it for themselves when they believe for reasons that preempt their own assessment of the evidence. McMyler argues that this analysis in terms of preemptive reasons_-as theorized in general by Raz (1990) and applied to epistemic authority by Zagzebski (2012) — blurs the clear distinction between two types of agent-based epistemic dependence: epistemically depending on other agents and epistemically depending on instruments and events. Impersonal instruments and events, McMyler argues, might be capable of providing us with preemptive reasons for belief, but we cannot cede rational responsibility for belief to an instrument or an event for the simple reason that they are not rational agents. Only other agents can rationally settle a theoretical or practical question for us. Indeed, when we believe on the authority of others, we are ceding part, but not all, of our rational responsibility. McMyler's explanation is that rational dependence requires epistemic responsibility on both sides of the dependence relation in the following way: deferring to an authority is an exercise of an irreducibly social rational capacity, viz., the joint project of making up one of the involved agents' minds in such a way that epistemic responsibility is distributed vis-à-vis the resulting belief.

The upshot of McMyler's discussion is that relying on instruments and events cannot be considered genuine epistemic dependence, insofar as genuine dependence on agents, one might argue, involves an element of epistemic responsibility that relying on instruments or events lacks, namely we cannot hold an instrument or an event responsible for not doing its part in the joint project of making up an epistemically dependent agent's mind. ${ }^{17}$

Sanford Goldberg ('Epistemically engineered environments', in this volume) sees things differently. Epistemic dependence on instruments does involve a share of epistemic responsibility on both sides: in particular, on the epistemically dependent agent and on the agents who participate in the design, manufacturing, testing, selling and repairing process of the instrument. ${ }^{18}$ Goldberg thinks that, while in testimonial exchanges the relevant dependence is framed in terms of an interpersonal entitlement that extends the supervenience basis of the justification of testimonial belief to processes that are involved in the speaker's production of testimony, in the case of instruments epistemic dependence should be viewed from the perspective of the social practices they are part of and, in particular, in terms of the expectations we are entitled to as participants of these practices. The idea is that agents regularly following the norms of these practices are in a position to infer that norms of interpretation and relia-

\footnotetext{
17 See McMyler (2011) for further discussion.

18 Goldberg calls this distinct form of epistemic dependence design dependence.
} 
bility of an instrument are broadly followed, and are thus in a position to form justified instrument-based beliefs. Moreover, insofar as we can hold others responsible for failing to do their part in social practices (e.g., in the design of an instrument), violations of these expectations can provide defeaters to the justification of instrument-based beliefs. ${ }^{19}$

Not content with this explanation, Goldberg reinterprets epistemic dependence on instruments as an instance of a broader form of epistemic dependence that happens in what he calls epistemically engineered environments. According to Goldberg, an epistemically engineered environment is "an environment that has been deliberately designed so as to decrease the cognitive burden on individual subjects in their attempts to acquire knowledge" (p. 13). In line with previous work (Goldberg 2010), he examines the key characteristics as well as the epistemic advantages of these epistemically protective environments. In particular, one such an advantage is that cognitively immature subjects who inhabit them can form justified and knowledgeable beliefs despite their lack of evidence, insofar as they form such beliefs in ways that the environment has been designed to support. By contrast, in less epistemically supportive environments agents have a greater cognitive load and consequently need a greater amount of epistemic work to acquire the relevant epistemic standings. In addition, Goldberg thinks that our expectations on mature subjects are more demanding than on young children (i.e., we place a greater epistemic burden on them), even if the former find themselves in epistemically protective environments. After all, such circumstances are not designed to provide epistemic support to them, but to immature subjects.

\subsection{Trusting experts}

Epistemic dependence on experts is pervasive in modern societies, where laypeople often have no other option but to rely on the judgment of specialists to achieve many of their epistemic goals. In a seminal paper on the topic, Goldman (2001) proposes several indirect ways for laypersons to track the reliability of experts and therefore to assess whether it is rational to trust them. Still, in some domains of specialization expertise seems to be required to identify and assess appropriate sources of information, including competent agents. C. Thi Nguyen ('Cognitive islands and runaway echo chambers: problems for epistemic dependence on experts', in this volume) calls these domains cognitive islands and argues that they can generate a particularly threatening version of what has been called echo chambers. In an echo chamber, information exchanges and belief formation are driven by mechanisms of repetition and amplification of specific beliefs and ideas, which causes tribalization and the spread of epistemic vices. While Nguyen thinks that we can identify experts in a cognitive island (contrary to what many think), this comes at a cost: the easy possibility of falling prey to what he calls runaway personal echo chambers, which are echo chambers that generate an epistemically detrimental kind of bootstrapping. In particular, when one is an expert in a cognitive island and one has to choose other experts on the basis of one's expertise, it might happen that one's cognitive abilities are off track. In that situation, chances are that one ends up choosing bad experts, which subsequently leads to an epistemically

19 See Goldberg (2012) for further discussion of the epistemology of instrument-based belief. 
pernicious self-reinforcement of one's own cognitive abilities and beliefs. Finally, one's self-reinforced abilities and beliefs are used to evaluate the expertise of others without further independent checks. If anything, this interesting phenomenon shows how widespread, yet epistemically fragile, our dependence on social methods of selfcheck and self-correction is, and urges to find ways to assess expertise distancing ourselves from our own cognitive abilities.

\subsection{The epistemology of disagreement}

The division of cognitive labor leads to mutual relations of epistemic dependence in many fields of inquiry, and many are its epistemic benefits. In their empirically informed paper 'Disagreement and the division of epistemic labor' (in this volume), Bjørn G. Hallsson and Klemens Kappel explore some of them in cases of deliberative settings where different group members disagree over a proposition. In these settings, the outcomes of inquiry are-as evidenced by empirical work in social psychology-epistemically better when disagreement encourages agents to some sort of motivated reasoning in defense of their respective beliefs. Hallson and Kappel are aware that this is at odds with many views in the epistemology of disagreement on what is rational to do upon discovering that one is in disagreement with someone else. Following some ideas in epistemic teleology (e.g., Carr 2017; Kopec 2017), they argue that it is rational to maintain belief in the face of disagreement when this promotes a deliberative division of epistemic labor that leads to a collectively better response to evidence. Their arguments also help shed light on the kind of epistemic dependence that arises in cases of disagreement. In particular, they think that while testimonial cases feature asymmetrical epistemic dependence of the hearer on the speaker, in disagreement cases the kind of epistemic dependence is mutual among all parties: in order to generate collective epistemic value-e.g., in order for the disagreeing parties to reach consensus on a correct answer that none believed to be correct prior to deliberation-, all parties in the disagreement need to follow the same kind of epistemic behavior, namely engaging in deliberation without first reducing confidence in their respective initial beliefs.

\subsection{The epistemology of testimony}

The most typical form of epistemic dependence happens in testimonial exchanges. It is certainly an open question how to model epistemic dependence on assertions by others, especially in connection with the many answers that have been given to the guiding question of the extensive literature on the epistemology of testimony-what is the epistemic status of testimony-based beliefs? - and particularly with regard to the normative conditions that different theories place on the testifier and the recipient of testimony.

One traditional way to frame the many ongoing disputes in this literature is in terms of the reductionism versus anti-reductionism divide. Very roughly, reductionists hold that testimony (unlike e.g., perception) is not a fundamental source of warrant or 
justification, while anti-reductionists deny this. ${ }^{20}$ In this volume, Mona Simion and Christoph Kelp ('How to be an anti-reductionist') sketch a promising version of what they call social anti-reductionism, i.e., the general view that the source of testimonial epistemic entitlement resides in the intrinsically social character of testimonial exchanges. Weak social anti-reductionist proposals, such as Graham $(2012,2015)$ and Greco (2015), hold that the internalization of social norms of proper testimony (Graham) or belonging to the same epistemic community (Greco) are sufficient grounds for testimonial entitlement; but they also hold that hearers either need to do some filtering work (Graham) or need to have positive reasons (e.g., independent inductive reasons) to trust speakers in the way required by their epistemic community and, contextually, by the practical tasks at hand (Greco). After offering extensive criticism of these views, Simion and Kelp sketch a strong version of social anti-reductionism, according to which neither positive reasons to trust testifiers, nor filtering work are needed: hearers are prima facie entitled to believe based on mere speakers' say so in virtue of the social norms that govern testimonial exchanges, and namely in virtue of social norms forbidding improper testimony. Key to their view is the idea that the existence of such norms turns taking others' words at face value into the default position in a testimonial exchange, if there is no strong overriding reason against it-e.g., in cases involving defeaters, they think that defeater-defeaters (positive reasons to believe what one is being told) are necessary for testimonial entitlement.

Epistemic dependence on the testimony of others may leave us on an epistemically vulnerable position, where an obvious and well-studied vulnerability is the possibility that one's testifier is deceptive. In an original contribution, John Greco ('The transmission of knowledge and garbage', in this volume) identifies another vulnerability not yet observed in the epistemology of testimony, which he dubs the garbage problem. According to this interesting problem, testimony transmits knowledge, but alongside knowledge, garbage (i.e., myths, rumors, prejudices, false beliefs, and so on) is also transmitted. The problem, then, is that of theorizing transmission so as to explain how knowledge can be transmitted right alongside garbage.

Greco starts by arguing, first, that several views in the epistemology of testimony are not able to give a satisfactory solution to the garbage problem and, second, that the best way to approach it is as a generality problem. Greco thinks that receivers of testimony are not able to discriminate knowledge from garbage within the class of testimony-based beliefs and, consequently, that adequate transmission channels must be conceived, at least in part, in terms of relevant ranges of information-e.g., medical information in an exchange between a doctor and a patient, information about mathematics in math class, and so on. According to Greco, the relevant informational ranges of transmission channels are determined by the practical tasks at stake in each conversational context, and especially by the epistemic community, insofar as epistemic communities are composed of people sharing information-dependent practical tasks as well as certain norms for assessing testimonial exchanges. In addition, Greco thinks that the norms for the acquisition of information are typically different from (and in particular, more demanding than) the norms for distributing information within

\footnotetext{
20 This is of course not the only way to frame the debate, nor the only dispute that is relevant in the rich literature on the epistemology of testimony. See Green (2008) for a helpful overview.
} 
an epistemic community. Interestingly, the latter applies to both hearers and speakers, who are assigned different epistemic roles. In this way, when both do their respective jobs properly, testimonial exchanges can be considered of high quality within the community. Like Goldberg, Greco further allows for the possibility that these testimonial exchanges may be subject to a form of diffuse epistemic dependence on the broader social environment-e.g., they may be further bolstered by licensing agencies, supervisors, fact checkers, and so on.

\subsection{Virtue epistemology}

In $\S 3$, we claimed that all forms of agent-based epistemic dependence have in common that they involve extra-agential factors. This characterization of epistemic dependence is potentially problematic for some virtue-theoretical accounts of knowledge, especially those that hold that knowledge is just a matter of exercising one's own cognitive abilities. In particular, Kallestrup and Pritchard $(2013,2016)$ have argued that the key tenet of so-called robust virtue epistemology - the thesis that knowledge is a cognitive success because of cognitive ability - is incompatible with both positive and negative knowledge-relative dependence. More specifically, they think that there are cases of knowledge-enabling dependence in which the fact that an agent's true belief amounts to knowledge significantly depends upon factors beyond her cognitive agency, such as certain cases of testimonial knowledge or cases of knowledge that results from extended cognitive processes (e.g., technological means). In addition, they also think that there are cases of knowledge-precluding dependence, in which extra-agential factors undermine one's knowledge-e.g., cases with the structure of the much-discussed fake barns case. ${ }^{21}$ Moreover, they further think that both kinds of cases prove robust virtue epistemology to be incompatible with these forms of epistemic dependence.

Duncan Pritchard ('Anti-risk epistemology and negative epistemic dependence', in this volume) argues that his new approach to knowledge, which he dubs anti-risk epistemology, is especially well positioned to handle cases of knowledge-precluding dependence, in comparison to its main competitor anti-luck epistemology (e.g., safetybased views) and robust virtue epistemology. Concerning the latter, Pritchard argues that such cases reveal that knowledge cannot be solely due to an exercise of cognitive agency, because the agents in question lack knowledge due to features of the purely modal environment that have nothing to do with the actual exercise of their reliable cognitive abilities (such as the easy possibility of seeing a fake barn). After discussing how anti-luck epistemology is aimed at excluding veritic epistemic luck in contrast to anti-risk epistemology, which is aimed at excluding veritic epistemic risk-as well as the theoretical implications of these different aims-, Pritchard explains the way in which the latter is better positioned when it comes to negative knowledge-precluding dependence. In a nutshell, he thinks that "what is distinctive of cases of negative epistemic dependence is not just that they involve veritic epistemic luck, but more specifically that they involve veritic epistemic risk" (p. 12). Key to his argument is the idea that while it has been disputed that veritic epistemic luck is incompatible with knowledge-after all, some epistemologists share the intuition that knowledge

21 See Goldman (1979) for the original formulation. 
is compatible with veritic luck-, ${ }^{22}$ it is indisputable that knowledge is incompatible with high levels of veritic epistemic risk. ${ }^{23}$

Fernando Broncano-Berrocal ('Epistemic dependence and cognitive ability', in this volume) agrees with Kallestrup and Pritchard's point that knowledge-precluding epistemic dependence proves some robust virtue epistemological views wrong, but this is because they target views according to which all it takes to manifest one's cognitive agency is the proper exercise of one's belief-forming abilities. However, as Broncano-Berrocal points out, the key tenet of robust virtue epistemology (that knowledge is a cognitive success that is due to properly exercised cognitive abilities) does not say anything about how the notion of cognitive ability should be understood and, therefore, does not mandate that knowledge must be exclusively due to our beliefforming abilities. Drawing on previous work (Broncano-Berrocal 2017, 2018), he argues that the notion of cognitive ability is not exhausted by abilities to produce true beliefs as outputs, but also includes what he calls precautionary abilities, which are dispositions to stop belief-formation when actual or modal circumstances are not suitable for forming beliefs in a reliable fashion. Once knowledge is understood as a cognitive success that is due to both types of cognitive abilities, he thinks that negative epistemic dependence is easily explainable. In particular, he argues that a failure to exercise one's precautionary abilities in the right way is what explains why purely modal facts prevent actual knowledge. Finally, his view also explains how other agents' cognitive abilities (e.g., in cases of testimonial knowledge) may have a bearing on the manifestation of a knower's cognitive agency. His conclusion is that robust virtue epistemology and epistemic dependence are not incompatible after all.

Finally, Walker Page ('Defending virtue epistemology: epistemic dependence in testimony and extended cognition', in this volume) disagrees with Kallestrup and Pritchard that robust virtue epistemology cannot handle cases of knowledge-enabling dependence and, in particular, cases of testimonial knowledge and knowledge from extended cognitive processes. Page first takes issue with some versions of robust virtue epistemology that have attempted to explain away these cases in terms of a certain understanding of what is for a knowledgeable belief to be due to cognitive ability, namely views according to which knowledge arises just in case cognitive success is attributable to (i.e., explained by) the exercise of cognitive ability either significantly or in the right way. ${ }^{24}$ Page is highly skeptical that these views can provide a convincing response to the challenge of positive epistemic dependence as they stand and moves on to advancing a positive proposal that interprets the troublesome cases of epistemic dependence as cases in which the relevant cognitive success is attributable to the abilities of an information system of which the knower is a part qua information processor - in addition, Page thinks that one of the knowers must play the role of evaluator. In this sense, Page's paper offers an analysis of the conditions that must be met for the exhibition and exercise of joint abilities, both in cases of testimonial and technological dependence.

\footnotetext{
22 See, e.g., Baumann (2014).

23 See Pritchard (2016a, b) for further discussion on the distinction between epistemic luck and epistemic risk and the two corresponding approaches to knowledge.

24 Greco $(2010,2012)$ offers these two versions of attributability views.
} 


\subsection{Intellectual autonomy}

In traditional epistemology, ideal knowers are depicted as autonomous knowers who never need to rely on others to acquire knowledge. However, as Fricker (2006: p. 243) notes, only "a superior being, with all the epistemic powers to find out everything she wanted to know for herself, could live up to this ideal of complete epistemic autonomy without thereby circumscribing the extent of her knowledge". Given our cognitive limitations, we have no other option but to rely on others. To which extent is this epistemically detrimental? Is it problematic at all? An ongoing debate in social epistemology — which has the notion of epistemic dependence at its core-aims to settle the question of whether or not (and to what extent) should we dispense with the individualistic ideal of intellectual autonomy. ${ }^{25}$

This debate mainly unfolds in terms of epistemic dependence on other agents (e.g., their testimony) in order to achieve epistemic standings (e.g., knowledge, justified beliefs). However, as we have seen, we can also epistemically depend on other factors (e.g., technological devices) to achieve different epistemic goals, such as some form of cognitive enhancement. J. Adam Carter (in 'Intellectual autonomy, epistemic dependence and cognitive enhancement', in this volume) explores how this form of epistemic dependence-viz., dependence on technology and medicine for the improvement of one's cognitives capacities - affects the ideal of intellectual autonomy. Contrary to a prima facie diagnosis that identifies a clear threat to intellectual autonomy in some cases of non-therapeutic cognitive enhancement, Carter argues that one's intellectual autonomy is challenged only when excessive dependence provokes an agential disconnect, by which he means a failure to meet certain conditions for cognitive integration, such as accessibility, automatic endorsement or cognitive ownership. According to Carter, cognitive enhancement can have a negative impact on cognitive integration if it prevents an epistemically respectable conception of the source of the reliability of one's beliefs or if it makes the cognitive ownership condition fail. In this way, although Carter thinks that cognitive enhancement is necessary for a valuable epistemic life, he also thinks that epistemic dependence of this form becomes disvaluable if it affects one's own capacity for self-direction. This is, in a nutshell, the potential threat that enhancing one's cognitive capacities poses to one's intellectual autonomy.

\section{Directions for further research}

As we have seen, there is no unique notion of epistemic dependence, but several kinds of epistemic dependence relations that can be classified in terms of (1) what kind of epistemic goals they aim at (e.g., achieving epistemic standings, enhancing cognitive capacities, complying with epistemic duties); (2) in terms of their relata (e.g., individual agents, beliefs, instruments, collectives, physical regularities, social environments, communities); and (3) in terms of their formal properties (e.g., reflexivity, transitivity, symmetry).

\footnotetext{
25 See Foley (2001), Fricker (2006), Vega (2007), Zagzebski $(2007,2013)$ Roberts and Wood (2007: Ch. 10) and Dellsén (Forthcoming) for different positions on the ideal of intellectual autonomy ranging from extreme epistemic egoism to epistemic universalism.
} 
Agent-based epistemic dependence (i.e., epistemic dependence of an agent on something or someone else) stands as the most philosophically interesting type of epistemic dependence, insofar as its different varieties bear on a plethora of epistemological issues. The essays of this special issue investigate epistemic dependence in connection with some of them, namely with topics such as epistemic rationality, epistemic authority, disagreement, testimony, expertise, virtue epistemology or intellectual autonomy; but agent-based epistemic dependence is relevant to other areas and topics in epistemology.

\subsection{Epistemology of education}

Epistemic dependence becomes especially relevant in the epistemology of education and some philosophical work has been done in this direction. For instance, Goldberg (2013) attempts to explain how the aim of education to free students to think for themselves is not in tension with the massive dependence of very young children on their teachers. In a similar fashion, Carter and Pritchard (2017) argue that the promotion of the student's cognitive success and the development of her incipient cognitive abilities can be interpreted as a positive form of epistemic dependence on an epistemically scaffolded environment. However, there is much more room for theorizing the distinctive relations of epistemic dependence that are relevant to education.

\subsection{Technological dependence}

We have just begun to explore the epistemic consequences of our massive dependence on technology — mainly on digital technologies - for covering our informational needs and achieving, more generally, our epistemic goals. A large part of our online epistemic lives, which include searching information and being exposed to information from people in our social networks, is governed by algorithms and analytics (e.g., search engine rankings, big data analytics, user behavior analytics) whose workings are not entirely transparent to us. In consequence, we are unable to assess whether they meet epistemic rather than commercial standards. In addition, we have dramatically increased the outsourcing of our cognitive tasks (e.g., remembering, calculating, navigating) to digital devices (e.g., to computer and smartphone apps). Many of these devices are particularly opaque, which means that even if they in fact offer reliable ways to form true beliefs, we cannot rule out the possibility of manipulation or even massive deception. Less skeptically, this sort of outsourced cognitive processing may positively or negatively affect our skills for achieving epistemic standings, such as our knowledge-gaining or reasoning skills. For instance, is the use of search engines detrimental to our cognitive abilities? One potential risk is that such interaction turns us in passive knowers. ${ }^{26}$ Other pressing issues arise in the context of technological dependence. For example, there is the related worry that outsourced cognitive processing may mean surrendering our cognitive abilities to the epistemic superiority of technological means, with the corresponding loss of intellectual autonomy.

$\overline{26}$ Lynch (2016) argues that this could be the upshot of heavily depending on what he calls Google-knowing. 


\subsection{Epistemic dependence and understanding}

So far, most philosophical work on epistemic dependence has revolved around knowledge- and justification-relative forms of agent-based dependence. However, there is little work on what is for an agent to be dependent on something or someone else to achieve epistemic standings different from knowledge and justified belief. Interestingly, we often depend on other people and instruments to gain understanding (whether propositional, objectual or understanding-why). For example, we ask for explanations and clarifications to people we know to understand what we aim to understand. We also resort to technological means to have access to information that is crucial for understanding propositions or topics we want to understand as well as for understanding why certain events happen. ${ }^{27}$ However, this seems to be in tension with the idea that to understand something one has to grasp it by oneself. ${ }^{28}$ Indeed, if it turns out that understanding cannot be transmitted as knowledge can, what is the contribution to our understanding of the agents and instruments we are epistemically dependent on in this distinctive way? Do they simply play the role of providers of information or do they play a more significant epistemic role?

\subsection{The epistemic risks of being epistemically dependent}

We have seen that epistemic dependence on others becomes negative if it has the consequence that one fails to achieve the epistemic goals the dependence relation is aimed at. For example, you may come to believe a true proposition $p$ without justification and then try to seek epistemic justification from the testimony of a person you take to be authoritative and reliable. If this person turns out to be a liar or unreliable, and you trust her testimony (not- $p$ ) nevertheless, you not only fail to gain justification, but you also lose your true belief. The moral is that relying on others to achieve epistemic goals you cannot achieve by your own always comes with epistemic risks.

Interestingly, there are other potential risks than just failing to achieve epistemic goals, namely the risk of becoming epistemically defenseless. Just as general dependence relations may become pathological when certain vulnerabilities of the dependent agents are exploited (e.g., by different forms of oppression), some relations of epistemic dependence may expose epistemically vulnerable agents to different forms of epistemic injustice (Fricker 2007), epistemic exploitation (Berenstain 2016) or epistemic corruption (Kidd Forthcoming). What kinds of epistemic dependence relations are more likely to make agents epistemically defenseless and expose them to forms of epistemic oppression and corresponding forms of epistemic privilege? One possible answer is that epistemic dependence relations that are sustained over time are in principle more liable to incur in such epistemic risks than occasional epistemic reliance-some examples of sustained epistemic dependence relations are the dependence of students upon their teachers in primary schools and the general public's dependence on mainstream media. Other related questions are: What makes an epis-

\footnotetext{
27 Interestingly, Lynch (2016) thinks that our massive dependence on Google increases our knowledge, but it reduces our understanding.

28 Pritchard (2016a, b) addresses a similar tension.
} 
temic dependence relation safe from epistemic oppression? What can the epistemically dependent agent do to protect herself or, eventually, to ameliorate the potential epistemic risks of being epistemically dependent? If some of those risks turn out to be ineliminable, to what extent is being epistemically dependent valuable ${ }^{29}$

\section{References}

Andersen, H. (2016). Collaboration, interdisciplinarity, and the epistemology of contemporary science. Studies in History and Philosophy of Science Part A, 56, 1-10.

Andersen, H., \& Wagenknecht, S. (2013). Epistemic dependence in interdisciplinary groups. Synthese, 190, $1881-1898$.

Audi, R. (1983). Foundationalism, epistemic dependence, and defeasibility. Synthese, 55, 119-139.

Baumann, P. (2014). No luck with knowledge? On a dogma of epistemology. Philosophy and Phenomenological Research, 89, 523-551.

Berenstain, N. (2016). Epistemic exploitation. Ergo: An Open Access Journal of Philosophy, 3, 569-590.

Broncano-Berrocal, F. (2017). A robust enough virtue epistemology. Synthese, 194, 2147-2174.

Broncano-Berrocal, F. (2018). Purifying impure virtue epistemology. Philosophical Studies, 175, 385-410.

Broncano-Berrocal, F. (Forthcoming). Epistemic dependence and cognitive ability. Synthese https://doi.org/ $10.1007 / \mathrm{s} 11229-017-1559-9$.

Carr, J. R. (2017). Epistemic utility theory and the aim of belief. Philosophy and Phenomenological Research. https://doi.org/10.1111/phpr.12436.

Carter, J. A. (Forthcoming). Intellectual autonomy, epistemic dependence and cognitive enhancement. Synthese. https://doi.org/10.1007/s11229-017-1549-y.

Carter, J. A., \& Pritchard, D. (2017). Epistemic situationism, epistemic dependence, and the epistemology of education. In A. Fairweather \& M. Alfano (Eds.), Epistemic situationism (pp. 168-190). Oxford: Oxford University Press.

de Ridder, J. (2014). Epistemic dependence and collective scientific knowledge. Synthese, 191, 1-17.

Dellsén, F. (Forthcoming). The epistemic value of expert autonomy. Philosophy and Phenomenological Research.

Dewitt, A. (2012). Group agency and epistemic dependency. Episteme, 9, 235-244.

Foley, R. (2001). Intellectual trust in oneself and others. Cambridge: Cambridge University Press.

Fraser, R. E. (2016). Risk, doubt, and transmission. Philosophical Studies, 173, 2803-2821.

Fricker, E. (2006). Testimony and epistemic autonomy. In J. Lackey \& E. Sosa (Eds.), The epistemology of testimony (pp. 225-253). Oxford: Oxford University Press.

Fricker, M. (2007). Epistemic injustice: Power and the ethics of knowing. Oxford: Oxford University Press.

Gelfert, A. (2013). Coverage-reliability, epistemic dependence, and the problem of rumor-based belief. Philosophia, 41, 763-786.

Goldberg, S. (2010). Relying on others: An essay in epistemology. Oxford: Oxford University Press.

Goldberg, S. (2011). The division of epistemic labor. Episteme, 8, 112-125.

Goldberg, S. (2012). Epistemic extendedness, testimony, and the epistemology of instrument-based belief. Philosophical Explorations, 15, 181-197.

Goldberg, S. (2013). Epistemic dependence in testimonial belief, in the classroom and beyond. Journal of Philosophy of Education, 47, 168-186.

Goldberg, S. (Forthcoming). Epistemically engineered environments. Synthese. https://doi.org/10.1007/ s11229-017-1413-0.

Goldman, A. I. (1979). What is justified belief? In E. Sosa \& J. Kim (Eds.), Epistemology. An anthology (pp. 340-353). Malden: Blackwell.

\footnotetext{
${ }^{29}$ Some of the papers of this special issue of Synthese were first presented in a workshop on Epistemic Dependence on Others and Artifacts held at the Autonomous University of Madrid in January 2016. We want to thank the participants of the workshop for valuable discussions on epistemic dependence as well as the invited and contributed authors of this special issue for their papers. The workshop and this research is supported by several research grants of the Spanish Ministry of Economy (FFI2013-45659-R, FFI201455256-REDT, FFI2017-87395-P).
} 
Goldman, A. I. (2001). Experts: Which ones should you trust? Philosophy and Phenomenological Research, $63,85-110$.

Graham, P. J. (2012). Testimony, trust, and social norms. Abstracta, 6, 92-117.

Graham, P. J. (2015). Epistemic normativity and social norms. In D. Henderson \& J. Greco (Eds.), Epistemic evaluation: Purposeful epistemology (pp. 247-273). Oxford: Oxford University Press.

Greco, J. (2010). Achieving knowledge. Cambridge: Cambridge University Press.

Greco, J. (2012). A (different) virtue epistemology. Philosophy and Phenomenological Research, 85, 1-26.

Greco, J. (2015). Testimonial knowledge and the flow of information. In D. Henderson \& J. Greco (Eds.), Epistemic evaluation: Purposeful epistemology (pp. 274-291). Oxford: Oxford University Press.

Greco, J. (Forthcoming). The transmission of knowledge and garbage. Synthese.

Green, C. R. (2008). The epistemology of testimony. Internet Encyclopedia of Philosophy. https://www. iep.utm.edu/ep-testi/. Accessed 15 Dec 2018.

Hallsson, G. B., \& Kappel, K. (Forthcoming). Disagreement and the division of epistemic labor. Synthese. https://doi.org/10.1007/s11229-018-1788-6.

Hardwig, J. (1985). Epistemic dependence. Journal of Philosophy, 82, 335-349.

Kallestrup, J., \& Pritchard, D. (2013). Robust virtue epistemology and epistemic dependence. In T. Henning \& D. Schweikard (Eds.), Knowledge, virtue and action: Putting epistemic virtues to work, ch. 11. London: Routledge.

Kallestrup, J., \& Pritchard, D. (2016). Dispositional robust virtue epistemology versus anti-luck virtue epistemology. In M. Fernández (Ed.), Performance epistemology: Foundations and applications, ch 2. Oxford: Oxford University Press.

Kidd, I. J. (Forthcoming). Epistemic corruption and education. Episteme. https://doi.org/10.1017/epi.2018. 3.

Kitcher, P. (1990). The division of cognitive labor. Journal of Philosophy, 87, 5-22.

Kopec, M. (2017). A pluralistic account of epistemic rationality. Synthese. https://doi.org/10.1007/s11229017-1388-x.

Korcz, K. A. (2015). The epistemic basing relation. Stanford Encyclopedia of Philosophy. https://plato. stanford.edu/entries/basing-epistemic/. Accessed 15 Dec 2018.

Kornblith, H. (1980). Beyond foundationalism and the coherence theory. The Journal of Philosophy, 77, 597-611.

Koslicki, K. (2013). Ontological dependence: An opinionated survey. In B. Schnieder, M. Hoeltje, \& A. Steinberg (Eds.), Varieties of dependence: Ontological dependence, grounding, supervenience, response-dependence (basic philosophical concepts) (pp. 31-64). Munich: Philosophia Verlag.

Lackey, J. (2008). Learning from words: Testimony as a source of knowledge. Oxford: Oxford University Press.

Lackey, J. (2015). A deflationary account of group testimony. In J. Lackey (Ed.), Essays in collective epistemology (pp. 64-94). Oxford: Oxford University Press.

Lewis, D. (1973). Counterfactuals. Hoboken: Blackwell.

Lynch, M. P. (2016). The Internet of us knowing more and understanding less in the age of big data. New York: W. W. Norton \& Company.

McMyler, B. (2011). Testimony, trust, and authority. Oxford: Oxford University Press.

McMyler, B. (Forthcoming). On not making up one's own mind. Synthese. https://doi.org/10.1007/s11229017-1563-0.

Nguyen, C. T. (Forthcoming). Cognitive islands and runaway echo chambers: problems for epistemic dependence on experts. Synthese. https://doi.org/10.1007/s11229-018-1692-0.

Oakley, T. (2006). A problem about epistemic dependence. In S. Hetherington (Ed.), Aspects of knowing (pp. 17-33). Amsterdam: Elsevier.

Page, W. (Forthcoming). Defending virtue epistemology: epistemic dependence in testimony and extended cognition. Synthese. https://doi.org/10.1007/s11229-017-1518-5.

Pritchard, D. (2015). Epistemic dependence. Philosophical Perspectives, 29, 305-324.

Pritchard, D. (2016a). Epistemic risk. Journal of Philosophy, 113, 550-571.

Pritchard, D. (2016b). Seeing it for oneself: Perceptual knowledge, understanding, and intellectual autonomy. Episteme, 13, 29-42.

Pritchard, D. (Forthcoming). Anti-risk epistemology and negative epistemic dependence. Synthese. https:// doi.org/10.1007/s11229-017-1586-6.

Raz, J. (1990). Practical reason and norms. Oxford: Oxford University Press. 
Roberts, C., \& Wood, J. W. (2007). Intellectual virtues: An essay in regulative epistemology. Oxford: Oxford University Press.

Simion, M., \& Kelp, C. (Forthcoming). How to be an anti-reductionist. Synthese. https://doi.org/10.1007/ s11229-018-1722-y.

Sylvan, K. (2016). Epistemic reasons II: Basing. Philosophy Compass, 11, 377-389.

Tahko, T. E., \& Lowe, E. J. (2015). Ontological dependence. Stanford Encyclopedia of Philosophy, 65, 353.

Vega, J. (2007). Epistemic merit, autonomy and testimony. Theoria, 23, 45-56.

Wagenknecht, S. (2014). Opaque and translucent epistemic dependence in collaborative scientific practice. Episteme, 11, 475-492.

Wagenknecht, S. (2015). Facing the incompleteness of epistemic trust: managing dependence in scientific practice. Social Epistemology, 29, 160-184.

Zagzebski, L. (2007). Ethical and epistemic egoism and the ideal of autonomy. Episteme, 4, 252-263.

Zagzebski, L. (2012). Epistemic authority: A theory of trust, authority, and autonomy in belief. Oxford: Oxford University Press.

Zagzebski, L. (2013). Intellectual autonomy. Philosophical Issues, 23, 244-261.

Zangwill, N. (Forthcoming). Epistemic/non-epistemic dependence. Noûs.

Publisher's Note Springer Nature remains neutral with regard to jurisdictional claims in published maps and institutional affiliations. 